\title{
Systems Integration: A Key Step Toward Strengthening Oral Health
}

\author{
Francisco H. Nociti Jr. * \\ Faculdade São Leopoldo Mandic, São Leopoldo Mandic Institute and Research Center, São Paulo, Brazil
}

Keywords: oral healthcare, integral care, systems approach, public healt, policies

\section{THE CHALLENGE}

A strong health system is critical if we are to improve health outcomes and accelerate progress toward increasing access to successful health programs and reducing disparities. Despite an established international consensus on the need to improve available health systems and/or create new ones, in general, there is no established framework for doing so no formula to apply for, and no package of interventions to implement. One may eventually note a lack of capacity to access weaknesses and constraints, and these existing omissions leave policymakers without scientifically sound ideas of how they should act, i.e., inform implementation and interventions. Transdisciplinary efforts are needed at the research, educational, clinical, and policy levels to bring together public and private sectors, citizens, clinicians, and researchers. A key operational element underlying integrated methods to advance healthcare for all communities is the use of system-based approaches.

\section{THE POTENTIAL FOR SYSTEM-BASED APPROACHES TO ADVANCE ORAL HEALTHCARE}

OPEN ACCESS

Edited and reviewed by:

Martha J. Somerman,

National Institutes of Health (NIH),

United States

*Correspondence:

Francisco H. Nociti Jr.

fhnociti@gmail.com

Specialty section:

This article was submitted to

Systems Integration,

a section of the journal

Frontiers in Dental Medicine

Received: 03 May 2021

Accepted: 28 May 2021

Published: 30 June 2021

Citation:

Nociti FH Jr (2021) Systems

Integration: A Key Step Toward

Strengthening Oral Health.

Front. Dent. Med. 2:704624.

doi: $10.3389 /$ fdmed.2021.704624
In the context of this Grand Challenge (GC), we consider the concept of a system-based approach as defined by Wanjek (1). The perspective that a systematic approach may assist in improving healthcare by considering the multiple elements involved in caring for patients and multiple factors influencing health.

The system-based approach uses a collection of analytical tools aimed at examining a given problem and the context that it is embedded in (2-4), e.g., a number of interconnected factors including genetic and epigenetic information of an individual, microbial profile, ethnicity, gender, demographics, and access to healthcare programs. This complexity requires a system-based approach to recognize the role of social, economic, and environmental factors and their interactions to successfully tackle chronic conditions. Although systems thinking has been recognized for over 40 years, it has only recently begun to be used in clinical settings to assist in appropriate diagnosis, treatment, and expected outcomes (5-10). A good example of the use of a system-based approach in the dental settings is the report by Briggs et al. (11), in which the health impacts in the levy of a soft drink industry were investigated. Analyses were performed considering a wide range of elements, such as stakeholders, media and the public positions, consumer acceptability, and reformulation and consumption, along with the health impacts, as part of a complex system. A further example where value was added by using a system-based approach was the FiCTION trial (12). Taking everything into account, the system-based approach has unprecedented potential, first in decoding the complexity of an entire health system and then in employing such knowledge to support and evaluate new interventions that may improve health and health equity. In due course, the use of a system-based approach to oral health research will assist us in defining (i) challenges in the development of data-intensive analytical methods and theoretical models, (ii) areas where 
additional transdisciplinary research is needed, (iii) the required workforce, (iv) how to use data and theoretical approaches to guide regulatory processes, and (v) best practices for data sharing, data collection, and clinical trial designs to enable systems thinking across dental-oral-craniofacial ecosystems in the context of systemic diseases and conditions.

\section{ORAL-SYSTEMIC HEALTHCARE INTEGRATION: THE CONTINUOUS DEMAND FOR MORE COOPERATION}

Following the conclusion of the studies by Flexner on medical education in 1910 (13), the Carnegie Foundation funded a similar survey on dental education. This process took about 5 years to be concluded, and in 1926, William Gies published his study, Dental Education in the United States and Canada, which tremendously impacted dentistry (14). One of the recommendations was a call for better integration between medicine and dentistry in order to best serve the needs of the population. Later, the 1995 report from the Institute of Medicine (IOM), Dental Education at the Crossroads: Challenges and Change (15), made 17 major recommendations, and a significant proportion of these recommendations focused on the relevance of better integration of educational programs between dentistry and other health professional programs, e.g., medicine, nursing, and pharmacy, in order to build a workforce that better reflects the diversity/needs of a given population. More recently, the IOM performed landmark studies to detail the oral health status in vulnerable and underserved populations of America $(16,17)$ and highlighted the need for the development of competent interprofessional teams to improve oral health. In this context, the relevance of integrating oral health into the overall health and the need for a closer alignment between dentistry and the other health professions stand clear.

Several initiatives worldwide have supported the move toward an integrated health system (IHS). At both levels, the educational and clinical care, the concepts of interprofessional educational initiatives (IPE) and interprofessional practice (IPCP) have been implemented at different levels to train future healthcare providers to facilitate and disseminate these models. The introduction of IPE programs has made significant progress over the years $(18,19)$. At the public health level, the recognition that integral healthcare (IHC) cannot be ensured without the inclusion of oral healthcare has led to the development of strategies in order to deliver better healthcare to a given population. The "Smiling Brazil" initiative is a good example of a strategy to integrate oral healthcare into a public healthcare system. In Brazil, nationwide surveys are used in order to generate epidemiological indicators, aiming at providing information for its public health decision-making process. In 2003, the National Household Survey (PNAD) detected that about $16 \%$ of the total Brazilian population (about 28 million people) had never visited a dental office, indicating, therefore, the urgent need to reassess the prevailing policies at that time. Thus, in 2004, the Smiling Brazil program was launched, and under this initiative, oral health was defined as one of the priority areas of the Brazilian unified healthcare system. Ten years after implementing the Smiling Brazil initiative, oral health epidemiological indicators, professional development, and the building of an oral healthcare network are some of the positive outcomes (20). Under these initiatives, Roncalli and his group found a reduction in decayed/missing/filled teeth (DMFT) from 2.8 in 2003 to 2.1 in 2010, a DMFT decline in teenagers, and an increase in the number of caries-free subjects (21). In addition, compared to the 2003 data, Peres et al. (22) described a significant reduction in the prevalence of tooth loss in teenagers (22).

Other examples of the benefits generated by transdisciplinary collaborations include the following: (i) the creation of the field of periodontal medicine based on an understanding of common mechanisms linked to periodontal diseases and others, as well as the differences, ultimately leading to improved preventive and therapeutic strategies for oral and overall healthcare (23), (ii) the identification of salivary gland fluids as biomarkers (diagnostics) for certain diseases and most recently as a reservoir for coronavirus $(24,25)$, and (iii) the discovery of potential links between microbes in the oral cavity with an intestinal inflammatory response (26), colon cancer (27), and Alzheimer's disease (28).

Importantly, healthcare providers will have to learn key skills, including communication, collaboration, humanism, and management of medically complex patients, in order to actively participate in this new era of exponential growth in the use of an evidence-based system integration approach to deliver healthcare.

\section{A CALL FOR INTERDISCIPLINARY AND TRANSDISCIPLINARY INITIATIVES}

Oral health is a critical aspect of overall health, and there is a price to be paid for not considering it. Governments and professional associations now recognize that professional silos present across healthcare providers (e.g., physicians, dentists, and others) are not in the best interests of developing patient-centered care models $(29,30)$. There is a need to break down the existing silos between healthcare professionals (HCPs) at all levels, from education and research to clinical practice so that integrated models are enabled with the ultimate goal of improving overall healthcare for all communities. There are terrific opportunities to apply collaborative initiatives across areas and sectors through research on the broad spectrum of determinants of oral diseases, aiming at addressing and exploring strategic routes linking behavioral, economic, environmental, psychosocial, political, and biological factors among other factors to the processes and outcomes of diseases. Contemporary challenges are complex, and addressing them requires integration and collaboration between experts with distinct backgrounds $(31,32)$. "We cannot resolve any of the big challenges we face in the future with just people who have sat in silos coming together" [cited in (33)]. It is now recognized that different expertise is mandatory to renew science and to provide state-of-the-art service, and interdisciplinary and transdisciplinary expertise have been recognized as the more critical ones. Although interdisciplinary and transdisciplinary 
efforts provide a great desire for bringing holistic, out-of-thebox thinking to an increasingly specialized workforce of experts, additional studies should be considered to better define the impact of interprofessional education and collaborative care on health outcomes for large populations. There is an opportunity for dental and other health professions to take the lead on such initiatives.

Despite the potential knowledge gained from interrogating dental-oral-craniofacial (DOC) conditions in the context of the whole body, physicians and dentists continue to be educated separately, employ a different language, and typically operate on different electronic file operational systems. As a result, oral healthcare has been left to the dentist, almost closing the doors for applying integrated care. A contemporaneous example of such a lack of collaborative strategies in resolving multidisciplinary health problems is the reports on a condition of exposed necrotic bone in oral surgery patients who were under antiresorptive agents named bisphosphonates (34). Patients described were patients with cancer being treated for hypercalcemia, metastasis, and other comorbidities, and although such patients were taking other medications, the use of intravenous bisphosphonates was a commonality. These cases were termed osteonecrosis of the jaw (ONJ). In the literature study, throughout these 18 years, dentists have been continuously called to work collaboratively with primary care physicians, endocrinologists, and oncologists to more comprehensively treat these patients. In contrast, dentists and scientists have been minimally asked to work as part of the team that will include immunologists, cancer researchers, and microbiologists to define the potential mechanisms involved with $\mathrm{ONJ}$ and also to establish scientific-based guidelines for care. Another illustrative example of the need for more intensive collaborative initiatives is the recognition that the mouth may serve as a reservoir of newly discovered bacteria and that leads to the design of more comprehensive therapies. Other examples underlying a call to action involve the emergence of new and/or little-known conditions that take the world by storm, including Zika virus and severe acute respiratory syndrome coronavirus 2 (SARS-CoV-2) pandemic.

The Learning Health System (LHS) is an example of an attempt to integrate the disciplines of biosciences (36). The LHS is an IHS "in which progress in science, informatics, and care culture align to generate new knowledge as an ongoing, natural by-product of the care experience and seamlessly refine and deliver best practices for continuous improvement

\section{REFERENCES}

1. Wanjek C. Systems biology as defined by NIH. Natl Instit Health Office. (2001) 19. Available online at: https://irp.nih.gov/catalyst/v19i6

2. Luke AD, Stamatakis KA. Systems science methods in public health: dynamics, networks and agents. Ann Rev Publ Health. (2012) 33:357-76. doi: 10.1146/annurev-publhealth-031210-101222

3. Mabrey PL, Kaplan RM. Systems science: a good investment for the public's health. Health Educ Behav. (2013) 40:9-12. doi: 10.1177/1090198113503469

4. McNiff S. Arts-based research. In: Knowles JG, Cole AL, editors. Handbook of the Arts in Qualitative Research. Thousand Oaks, CA: Sage (2008). p. 29-40. in health and healthcare" [cited by Institute of Medicine (36)]. It is now time for a transformation where digitalized health files will go beyond simply accounting for portions of individual care. These documents must also make ongoing assessments available and provide information on therapy outcome, effectiveness, and the potential association between diseases that will later be collectively assessed and will be used to making informed decisions at the individual and collective levels. The advance of such systems will highly depend on the collaboration of several areas, such as education, innovation, and research, occurring at the convergence of multiple and distinct disciplines (35).

\section{FINAL REMARKS}

It is evident that changes are necessary to improve the current healthcare systems, given their safety, quality, cost, and complexity challenges. In this context, a system-based approach to research, from basic to clinical, by increasing our understanding of how different parts of the system interact with one another and by developing models for implementation of evidence-based approaches will result in huge benefits for care delivery to all communities.

Despite all the actions and policy support, the transformational capacity and the possibilities of interdisciplinary and transdisciplinary research and healthcare approaches, as well as their critical role in shaping knowledge to approach future questions with regard to health professions, including dentistry and medicine, have historically developed independently, with separate education, clinical networks, records, funding, and insurance arrangements. We are convinced that it is critical to overcome this divide in order to perform better and maybe then we can put "the mouth back in the body."

\section{AUTHOR CONTRIBUTIONS}

FN prepared the manuscript, confirms being the sole contributor of this work and has approved it for publication.

\section{FUNDING}

The author greatly appreciates the support of the National Council for Scientific and Technological Development, Brazil (CNPq, grant \# 301086/2019-2). 
8. Kitson A, Brook A, Harvey G, Jordan Z, Marshall R, O'Shea R, et al. Using complexity and network concepts to inform healthcare knowledge translation. Int J Health Pol Manage. (2018) 7:231-43. doi: 10.15171/ijhpm.2017.79

9. Rehfuess E, Stratil J, Scheel IB, Portela A, Norris SL, Baltussen R. The WHOINTEGRATE evidence to decision framework version 1.0: integrating WHO norms and values and a complexity perspective. BMJ Global Health. (2019) 4:e000844. doi: 10.1136/bmjgh-2018-000844

10. Petticrew M, Knai C, Thomas J, Rehfuess EA, Noyes J, Gerhardus A, et al. Implications of a complexity perspective for systematic reviews and guidelines development in health decision making. BMJ Global Health. (2019) 4:e000899. doi: 10.1136/bmjgh-2018-000899

11. Briggs ADM, Mytton OT, Kehlbacher A, Tiffin R, Elhussein A, Rayner M, et al. Health impact assessment of the UK soft drinks industry levy: a comparative risk assessment modelling study. Lancet Public Health. (2017) 2:e15-22. doi: 10.1016/S2468-2667(16)30037-8

12. Maguire A, Clarkson JE, Douglas GV, Ryan V, Homer T, Marshman Z, et al. Best-practice preventionalone or with conventional or biological caries management for 3-to 7-year-olds: The FiCTION three-arm RCT. Health Technol Assess. (2020) 24:1-174. doi: 10.3310/hta24010

13. Flexner A. Medical Education in the United States and Canada: A Report to the Carnegie Foundation for the Advancement of Teaching. New York, NY: Carnegie Foundation (1910).

14. Gies WJ. Dental Education in the United States and Canada: A Report to the Carnegie Foundation for the Advancement of Teaching. New York, NY: Carnegie Foundation (1926) doi: 10.1097/00007611-192709000-00025

15. Field MJ. Dental Education at the Crossroads: Challenges and Change. An Institute of Medicine Report. Washington, DC: National Academies Press (1995).

16. Institute of Medicine. Advancing Oral Health in America. Washington, DC: National Academies Press (2011)

17. Institute of Medicine. National Research Council. Improving Access to Oral Health Care for Vulnerable and Underserved Populations. Washington, DC: National Academies Press (2011).

18. Palatta A, Cook BJ, Anderson EL, Valochovic RW. 20 years beyond the crossroads: the path to interprofessional education at U.S. dental schools. $J$ Dent Educ. (2015) 79:982-96. doi: 10.1002/j.0022-0337.2015.79.8.tb05990.x

19. Zorec J, Raehl C. Interprofessional education accreditation standards in the USA: a comparative analysis. J Interprof Care. (2013) 27:123-30. doi: 10.3109/13561820.2012.718295

20. Pucca GA, Gabriel M, de Araujo ME, de Almeida FCS. Ten years of a national oral health policy in Brazil: innovation, boldness, and numerous challenges. $J$ Dent Res. (2015) 94:1333-7. doi: 10.1177/0022034515599979

21. Roncalli AG, Sheiham A, Tsakos G, Watt RG. Socially unequal improvements in dental caries levels in Brazilian adolescents between 2003 and 2010. Community Dent Oral Epidemiol. (2015) 43:317-24. doi: 10.1111/cdoe.12156

22. Peres MA, Barbato PR, Reis SC, Freitas CH, Antunes JL. Tooth loss in Brazil: analysis of the 2010 Brazilian oral health survey. Rev Saude Publica. (2013) 47:78-89. doi: 10.1590/S0034-8910.2013047004226

23. Genco RJ, Sanz M. Clinical and public health implications of periodontal and systemic diseases: an overview. Periodontol. (2020) 83:7-13. doi: $10.1111 /$ prd.12344

24. Xu J, Li Y, Gan F, Du Y, Yao Y. Salivary glands: potential reservoirs for COVID-19 asymptomatic infection. J Dent Res. (2020) 99:989. doi: $10.1177 / 0022034520918518$
25. Rodrigues RPCB, de Andrade Vieira W, Siqueira WL, Blumenberg C, de Macedo Bernardino Í, Cardoso SV, et al. Saliva as an alternative to blood in the determination of uremic state in adult patients with chronic kidney disease: a systematic review and meta-analysis. Clin Oral Investig. (2020) 24:2203-17. doi: 10.1007/s00784-020-03340-2

26. Atarashi K, Suda W, Luo C, Kawaguchi T, Motoo I, Narushima S, et al. Ectopic colonization of oral bacteria in the intestine drives TH1 cell induction and inflammation. Science. (2017) 358:359-65. doi: 10.1126/science. aan4526

27. Mima K, Nishihara R, Qian ZR, Cao Y, Sukawa Y, Nowak JA, et al. Fusobacterium nucleatum in colorectal carcinoma tissue and patient prognosis. Gut. (2016) 65:973-80. doi: 10.1136/gutjnl-2015310101

28. Dominy SS, Lynch C, Ermini F, Benedyk M, Marczyk A, Konradi A, et al. Porphyromonas gingivalis in Alzheimer's disease brains: evidence for disease causation and treatment with small-molecule inhibitors. Sci Adv. (2019) 5:eaau. doi: 10.1126/sciadv.aau3333

29. Landman N, Aannestad LK, Smoldt RK, Cortese DA. Teamwork in health care. Nurs Adm Q. (2014) 38:198-205. doi: 10.1097/NAQ.000000000000 0037

30. Vallis M. A collaborative approach to a chronic care problem: an academic mentor's point of view. Healthc Pap. (2016) 15:74-9. doi: 10.12927/hcpap.2016.24543

31. Sillitoe P. Interdisciplinary experiences: working with indigenous knowledge in development. Interdisc Sci Rev. (2004) 29:6-23. doi: 10.1179/030801804225012428

32. Farrell KN. Snow White and the wicked problems of the West: a look at the lines between empirical description and normative prescription. Sci Techn Hum Values. (2011) 36:334-61. doi: 10.1177/0162243910385796

33. Lyall C. Exploring Interdisciplinary Careers, 2nd INTREPID Policy Brief, COST Action TD1408, 4 April. (2019). Available online at: http://www.intrepid-cost. eu/intrepid-reports-and-policybriefs

34. Migliorati CA. Bisphosphanates and oral cavity avascular bone necrosis. J Clin Oncol. (2003) 21:4253-4. doi: 10.1200/JCO.2003.99.132

35. Friedman C, Rubin J, Brown J, Buntin M, Corn M, Etheredge L, et al. Toward a science of learning systems: a research agenda for the highfunctioning learning health system. J Am Med Inform Assoc. (2015) 22:43-50. doi: 10.1136/amiajnl-2014-002977

36. Institute of Medicine. Digital infrastructure for the learning health system: the foundation for continuous improvement in health and health care. In: Grossman C, Powers B, McGinnis JM, editors. The Foundation for Continuous Improvement in Health and Health Care Workshop Series Summary. Washington, DC: National Academies Press (2011), 1-311.

Conflict of Interest: The author declares that the research was conducted in the absence of any commercial or financial relationships that could be construed as a potential conflict of interest.

Copyright (c) 2021 Nociti. This is an open-access article distributed under the terms of the Creative Commons Attribution License (CC BY). The use, distribution or reproduction in other forums is permitted, provided the original author(s) and the copyright owner(s) are credited and that the original publication in this journal is cited, in accordance with accepted academic practice. No use, distribution or reproduction is permitted which does not comply with these terms. 